Zhong, L. (2017). Indicators of Digital Leadership in the Context of K-12 Education. Journal of Educational

Technology Development and Exchange, 10(1), 27-40.

\title{
Indicators of Digital Leadership in the Context of K-12 Education
}

\author{
Lin Zhong \\ Southern Illinois University
}

\begin{abstract}
International Society for Technology in Education Standards for Administrators (ISTE-A, 2009) has been published for six years and but few studies have been done to indicate digital leadership indicators. This qualitative study aims to explore digital leadership indicators in the context of K-12 education based on ISTE-A standards. Results show that visionary leadership is indicated as integrated technology vision and technology plan support by all stakeholders. Indicators of digital age learning culture include sufficient devices, technology modeling, and effective technology utilization. Digital learning opportunities and digital learning community are indicators of professional development. Indicators of systemic improvement include maximized learning achievement, competed personnel, and strategic partnership. Digital citizenship is indicated as digital filter.
\end{abstract}

Keywords: Digital leadership, ITSE-A, K-12

\section{Introduction}

The emerging instructional technology has significant effect on not only higher education but also K-12 classrooms. Technology has been defined as a must-do requirement instead of a preference or choice for 21 st century learners. According to the Common Core State Standards (CCSS) Initiative released at 2009 and adopted by 45 states, K-12 students must be able to communicate, collaborate, produce, and publish their work by using technology with guidance from adults. The shift from learning about technology to learning with technology does not only require
K-12 students but also K-12 educators to treat technology as an embedded part of teaching. Teachers need to adjust the ways of teaching so that students can meet the requirements of 21 st century learning and CCSS. As school leaders, K-12 principals play a vital part in leading school transform from technology-referenced learning environment to technology-based learning community to meet 21 st century learning requirements.

International Society for Technology in Education Standards for Administrators (ISTE-A, 2009) has been published for five years and numerous literatures utilized 
the ISTE-A standards to guide the studies. Most studies utilized ISTE-A standards as an assessment tool and investigated the relationship between technology leadership practices and school effectiveness including teaching, learning, and administration (Karnjanapun, 2013; Weng \& Tang, 2014; Metcalf, 2012). However, few studies have been done to indicate specific leadership performance indicators within the ISTE-A standards. Since ISTE-A standards only provided descriptions of the expertise and responsibilities that school administrators should cover, researching the detailed digital leadership practices and providing concrete examples of successful digital leadership implementations are essential for K-12 school principals to understand and align their practices with ISTE-A standards.

This study aimed to investigate detailed descriptive digital leadership performance indicators within the ISTE-A standards. Digital leadership in this study was defined as using instructional technology, including digital device, service, and resources, to inspire and lead school digital transformation, create and sustain digital learning culture, support and enhance technology-based professional development, provide and maintain digital organization management, and facilitate and manage digital citizenship. School digital transformation was referred to the period of Common Core implementation. This study makes contribution to the digital leadership field by investigating and explaining qualitative digital leadership indicators that has not been addressed in previous literatures. This research provides K-12 principals with concrete examples of digital leadership that constituted with a series of successful practices and tips.

\section{Literature Review}

Research has demonstrated that digital leadership improves and encourages digital teaching and learning (Richardson, Bathon, Flora \& Lewis, 2012). Principals' attitude towards technology affects teaching effectiveness and teachers' ability of integrating technology into teaching. Chang (2012) studied the relationship between principals' digital leadership and K-12 teachers' teaching effectiveness. Results showed that principals' technology knowledge and skills directly impacted on teachers' technology integration in teaching. Raman, Don, and Kasim (2014) also reported positive impact of principals' leadership on the use technology in teachers' classrooms. The study pointed out that principal worked as the role model in school's daily life and affected teachers' behaviors through their interaction.

Currently, there were no clear descriptions of what elements can be used to indicate successful digital leadership. Chang (2012) chose Principals' Technological Leadership Instrument that categorized digital leadership as vision, professional development, infrastructure support, evaluation, and communication. Garcia (2014) considered digital leadership as familiar with technology, use information retrieval, communicate with stakeholders, and manage resources. However, Chang's (2012) and Garcia's (2014) categories did not include all the elements, such as digital citizenship. Duncan (2011) contained all necessary elements by utilizing the Principals Technology Leadership Assessment (PTLA) as the research instrument to describe principals' digital leadership. However, PTLA instrument was developed from previous ISTE-A standard that was known as NETS-A standards (2002). It is not appropriate to use a ten-year old instrument to describe today's digital leadership. There was a need to explore 
what indicators can be used to describe today's digital leadership.

The purpose of this study is to explore digital leadership indicators in the context of K-12 education based on the International Society for Technology in Education Standards for Administrators (ISTE-A). ISTE-A was utilized to develop research questions and data collection instrument. This case study fills in this gap by observing, interviewing, and describing K-12 principals' digital leadership practices in real school settings and providing digital leadership indicators within K-12 context. According to ISTE-A standards, digital leadership was conceptualized as inspire and lead school transformation through technology, create and sustain digital learning culture, support technology-based professional development, provide digital leadership and management, and facilitate and manage social, ethical, and legal issues. The following research questions were proposed to guide this study:

1.What are the indicators of visionary leadership through technology?

2.What are the indicators of creating and sustaining digital learning culture?

3. What are the indicators of supporting technology-based professional development?

4.What are the indicators of providing digital leadership and management?

5. What are the indicators of digital citizenship?

\section{Methods}

A qualitative case study formed the methodological framework in this study to address the research question. Qualitative research methodology is well suited for this study to explore real-life experiences within a unique context through detailed and in-depth data collection involving interviews (Creswell, 2013; Seidman, 2012; Yin, 2013). In other words, qualitative rather than quantitative research methodology was more suitable to explore learning experiences because qualitative research focused on in-depth understanding of principal's digital leadership experience instead provided treatments of specific issue.

\subsection{Setting}

The research setting was three K-12 schools (labeled as school A, B, and C) located at a southern town in Mississippi. All of the three schools are located at the same school district.

School A is a lower elementary school that serves over six hundreds students from grade two and grade three. School hours at school A is from 7:40am to 2:20pm. Macbook and interactive white board are the primary technology devices for teaching. iPad and Chromebook are the primary technology devices for student learning. School A has two computer labs for the need of computer class. Technology integration at school A focuses on classroom management and school administration. Teachers use iPad apps to manage classroom behaviors. Principal uses school management software, mobile phones, and other mobile devices for teaching evaluation.

School B is a primary school that has more than eight hundreds students who are kindergarten and grade one students. Students stay at school from 7:40am to 2:10pm. Similar to school A, Macbook and interactive white board are the primary technology devices for teaching. iPad and Chromebook are the primary technology devices for student 
learning. School B has one computer lab for computer class. Because students in school B are young students, teachers in school B like to use video, pictures, and games in teaching to get students involved. All the digital resources used in teaching will be set up at the computer in classroom so that students can continue use the resources for practice after class time.

School $\mathrm{C}$ is a high school that has enrollment of about five hundreds student from grade nine to grade. Student stay at school from $8 \mathrm{am}$ to $3 \mathrm{pm}$. Besides basic technology equipments, school $\mathrm{C}$ has two brand new Mac labs that most computer classes are taught at the Mac labs. Because students at school $\mathrm{C}$ are high school students, the technology integration at school $\mathrm{C}$ focuses on student-centered researching project and other higher level of technology use, such as online learning. Digital resources are also provided for students for the need of selfdirected learning activities such as SAT testing practice.

Most of the technology support in the three schools come from the technology department of the school district. They share one instructional technologist with each other. Schools can send technical support requests directly to the instructional technologist through email, phone calls, and district website. Then instructional technologist will schedule training time and days with schools based on the requests.

\subsection{Participants}

Purposeful sampling method, primarily criterion sample was used in this study to gather information-rich feedback from individuals. Criterion sampling means selecting individuals who met a specific criterion. Criterion for this study was people who were in-service K-12 principals. Participants were recruited from the local K-12 schools with help of the technology director in the technology department of the school district.

The participants in this study were three $\mathrm{K}-12$ principals who served in the school district more than five years. These participants were chosen because they could provide rich information regarding digital leadership and how technology influenced their leadership and the campus. For the purpose of privacy protection, pseudonyms were used throughout the date collection process whenever possible, with all transcripts utilizing only pseudonyms. All names used in this study were fictional names.

\subsection{Data collection and analysis}

Three types of data collections were conducted in this study: (1) in-depth interviews, (2) participants' observations, and (3) documents analysis.

Participants were interviewed with twelve open-ended questions that targeted on exploring K-12 principals' digital leadership experience. Each participant was interviewed no more than one hour. During the interview, the researcher listened to principal's reallife experience related to digital leadership, learned about their feelings in the process of performing digital leadership, and understood their beliefs from the subjects' point of view. Participant observations were conducted in classrooms and computer labs. The relevant documents, including lesson plan, syllabus, school handbooks, district handbooks, and ITSE-A standards were collected and analyzed. Reviewing the related documents helped researcher gain a clear idea of digital leadership implementation. Data analysis and interpretations were conducted through (1) coding interviews transcriptions, observation notes, and documents analysis notes, (2) reading all data and generating categories, 
themes, and patterns, and (3) writing the findings according to the research questions.

\section{Findings}

Findings showed that principals focused on teachers' technological professional development when they were asked to describe digital leadership strategies.Few support was found to support digital citizenship through principals. The findings were organized in Table 1. technology vision and technology plan support by all stakeholders.

Integrated Technology Vision. Technology is an integrated part of learning and teaching. All participants reported that they realized technology was part of today's life. Technology means digital administration, digital learning, and digital teaching. Students are growing up with technology. It was impossible to move technology off the campus. It is necessary and important for schools to provide digital learning opportunities and help students

Table 1. Indicators of K-12 digital leadership

\begin{tabular}{|c|l|}
\hline \multirow{4}{*}{ Visionary Leadership } & Integrated technology vision \\
\cline { 2 - 2 } & Technology plan support by all stakeholders \\
\hline \multirow{4}{*}{ Digital Age Learning Culture } & Sufficient devices \\
\cline { 2 - 2 } & Technology modeling \\
\cline { 2 - 2 } & Effective technology utilization \\
\hline \multirow{3}{*}{ Professional Development } & Digital learning opportunities \\
\cline { 2 - 2 } & Digital learning community \\
\hline \multirow{3}{*}{ Systemic Improvement } & Maximized learning achievement \\
\cline { 2 - 2 } & Competent personnel \\
\cline { 2 - 2 } & Strategic partnership \\
\hline Digital Citizenship & Digital filter \\
\hline
\end{tabular}

\subsection{What are the indicators of visionary leadership through technology?}

Visionary leadership is described as inspiring and leading "development and implementation of a shared vision for comprehensive integration of technology to promote excellence and support transformation throughout the organization" (ISTE-A, 2009). Findings of this study showed that visionary leadership could be indicated as integrated get the digital learning experience. Schools should connect the kids with the digital world where they are coming and growing. One of the teachers described her experience of using blogs to have students do homework on blogs.

Technology plan support by all stakeholders. Technology needs support from all stakeholders. Providing digital learning environment is an impossible task without support from all stakeholders. All teachers are 
required to attend routine technology meetings in which a district instructional technologist comes and updates each department of teachers on current technology in the district. The vision for technology at school is to ensure that technology is incorporated into all classrooms to enhance student learning. Upon completion of the required routine training, teachers work within their departments to ensure that students are exposed to a technology rich classroom.In addition, all principals showed that they understood the importance of Parents and Teachers Organization (PTO). PTO plays an important role in creating digital learning environment. PTO in school B helps students switch from $\mathrm{PC}$ to Mac. Parents purchased Mac and voluntarily helped schools with computer class.At the very beginning of the year, schools performed an assessment of what the school needs, principals worked closely with the boards to find out what schools need and what teachers in classrooms need. So as long parents can see they will impact the instruction and help teachers with their instructional strategies, parents will participate.

\subsection{What are the indicators of creating and sustaining digital learning culture?}

Digital age learning culture is described as creating, promoting, and sustaining "a dynamic, digital-age learning culture that provides a rigorous, relevant, and engaging education for all students" (ISTE-A, 2009). Findings of this study showed that digital age learning culture could be indicated as sufficient devices, technology modeling, and effective technology utilization.

Sufficient devices. Hardware is the basis of digital transformation. Hardware equipped with appropriate software makes learning and teaching faster and easier. All participants shared with researcher that Wifi was covered in the whole campus for years. Schools encourage students to bring their own devices such as smartphone to school for instructional purposes. Each classroom is equipped with an interactive whiteboard. Flip charts are saved for review. Instructors can share their flip charts and are able to modify the file to accommodate future instruction. Each instructor is equipped with a MacBook. Library is equipped with computers and a technology specialist. Students are able to use the library resources such as computers. High schools have a consulting center that helps students with their college application, SAT, and other instructional needs. iPad is used to manage students' behavior, share info with parents, and evaluate teaching.

Technology modeling. Modeling technology through administration activities is important for promoting digital teaching and learning. Principal models the technology use such as how specific software or app use in administration. In addition, principal from school B promoted using Twitter as a way of communicating with teachers and students. Teachers are required to update their teaching website based on parents' and students needs. If parents prefer paper-based materials, instructors can mail the materials such as hard copy newsletter. If parents prefer digital resources, teachers will upload materials such as lesson plan, newsletter to their teaching website. In addition, social media such as Facebook is used to share info with teachers and parents.

Effective technology utilization. Utilization of available resources promotes digital transformation. All principals emphasized that student achievement was an important priority. Therefore, many strategies and technology were used to ensure that the diverse needs of all students are being met. The following list is an example of technology tools used in schools. 
Plato-students use this technology software as a tutorial for credit recovery. As the student progresses through the program, the program adjusts to the process mastery of the student.

USA Test Prep-students use USA Test Prep for reinforcement review in preparation for SATP Test. Similarity to Plato, USA Test Prep also adjusts to the progress mastery of the student.

Edgenuity-computer software used for instruction at the Alternative School level. this program is designed to meet the needs of students to ensure that when the student returns to the regular school environment gaps in instruction will be minimalized. Additionally, Edgenuity will be implemented into the regular education curriculum to reinforce Core Curriculum, Concept and Credit Recovery, Instructional Services, Career Education, Higher Education, Summer School Programs, and Advanced Placement.

ICAP-Career Readiness software used with all students on campus to ensure students are prepared to transfer from high school to college or from high school to a career.

Driver's Education Online Tutorial-This online tutorial site is used among students to review and road signs, symbols, and traffic laws as they pertain to the state of MS.

Bookflix-it is an interactive book software program. It provides fictional books for kids. The computer tells the story and the book is animated. It also provides non-fiction pdf books for teachers.

\subsection{What are the indicators of supporting technology-based professional development?}

Professional development is described as promoting "an environment of professional learning and innovation that empowers educators to enhance student learning through the infusion of contemporary technologies and digital resources" (ISTE-A, 2009). Findings of this study showed that professional development could be indicated as digital learning opportunities and digital learning community.

Digital learning opportunities. Professional development doesn't just mean training. Principal A said, "Teachers are not evaluated by the training they participated. I take pictures and also record the class as evidence in my phone and iPad. With the app in iPad, I can leave comments to specific teacher and also teacher can see the comments and get feedback immediately." Latest technologies are delivered to teachers via e-mail, district trainings, and software companies. Teachers can view the technology list and decide what they want to learn and when they are available to learn. Supporting teachers based on their needs is more important than affording teachers what schools have.

Digital learning community. Building learning community to promote communication and collaboration is another strategy to support professional development. Teachers can request learning group after school time. Teachers stay at school and learn from other teachers and support each other. District also provides support for teachers. Teachers can report the technology they want and need. Then instructional technologist learns the technology and trains the teachers. District also shares technology such as software, app, and technological services with schools. Teaches are required to complete various online subject area trainings and district trainings. The subject area technology trainings equip teachers with strategies to use in the classroom that promote higher level thinking skills and problem solving skills in 
students. All the teachers are required to attend technology meetings during their planning periods. Instructional technologists are on hand during the professional development meetings to support teachers with the various technologies used in their classroom. Instructional technologists inform teachers of any update that they need to be aware of regarding the equipment in the classroom. The instructional technologists also answer questions and demonstrate how the various technologies can be used to increase student knowledge and achievement in the classroom. Routinely all administrators, teachers, and staff are involved in communities that promote and encourage the use of technology to improve school communication and productivity. All school communication currently in place is routinely updated with all school personnel. Principal from oak grove lower elementary uses Facebook as a way of communication and collaboration. She posts info there and parents' followers are able to see these info. She is promoting the use of twitter in her school. She uses technology such as SchoolStatus to collect evidence of teaching and administration. She takes pictures and records when she observes class. For parents, they will get a text reminder if school have event. Communication between school and parents is text-based communication because this way is simple and quick.

\subsection{What are the indicators of systemic improvement?}

Systemic improvement is described as providing "digital age leadership and management to continuously improve the organization through the effective use of information and technology resources" (ISTE-A, 2009). Findings of this study showed that systemic improvement could be indicated as maximized learning achievement, competent personnel, and strategy parterships.
Maximized learning achievement. Purposefully maximize learning achievement through appropriate use of technology. All principals reported that they provided learning devices such as interactive board to ensure students and teachers are involved in digital learning environment. All schools have purchased chrome books and ebooks that all students are able to access. SAMS7, which is a management app, is being used to manage all attendance, tardiness, registration, scheduling, discipline, and absences. The technology plan is sustained by employing personnel to handle attendance, registration, scheduling, and computer lab tutorials. The financial support for the personnel is allotted through district budget. Principal uses Feedback, which is a digital management app, to collect evidence and comment teachers' instruction. She goes to school with her walky-talky, phone, and iPad everyday. Teachers and administrators use Google docs to share document such as lesson plan. Principals improve staff performance and student learning by collaboration.

Competent personnel.Recruit and retain highly competent personnel to advance academic and operation goals. Teachers who are proficient at technology will model their technology and help with inside training. They also can get financial reward such as salary increase. The use of technology is assessed and evaluated through lesson plans for student learning and reports from SAMS for communication and productivity. Excel is used to analyze data and interpret the results. The findings are shared with teachers via e-mail. Teachers also use School Wires to communicate with student's families. SchoolStatus and Feedback is used to manage, evaluate, and assess operational systems.

Strategic partnerships. Establish and leverage strategic partnerships to support systemic improvement. Teachers share flip charts with each other. After school time, 
teachers communicate, discuss, and learn with other teachers. Teachers learning group is built to promote communication and collaboration. Principal $\mathrm{C}$ reported that her campus was in the process of slowly replacing all technology. Chromebook has been ordered as well as desktop computers. School website has all the information of teachers, parents, and administrators. All the teachers are list in the school website. Students and parents are able to access teachers' websites and instructional resources. Parents can get students' attendance report, PTO information, registration, transportation, and students' handbook information.

\subsection{What are the indicators of digital citizenship?}

Digital citizenship is described as modeling and facilitating "understanding of social, ethical, and legal issues and responsibilities related to an evolving digital culture" (ISTE-A, 2009). Findings of this study showed that digital citizenship could be indicated as digital filter.

Digital filter. All principals reported that everyone had equitable access to resources. All learners have access to computer labs and library computers at all times. Teachers have access to computers in their classrooms via laptops and desktop computers. Schools also provide free digital resources for parents who do not have access at home. Principals use digital tools to provide a safe and legal digital learning environment. All students and teachers will sign a technology agreement form in which they agree not to do anything unlawful with technology. Additionally, filters are installed at all schools to ensure that students do not access inappropriate web sites.

\section{Discussion}

Findings from this study have provided clear indicators of K-12 digital leadership that are new findings, which have not been included in Garcia's (2014) study. Technology filter was identified as indicator of digital citizenship. According to the participants, most digital citizenship support comes from school district. None of the schools in this study have reported digital leadership related to digital citizenship. All the schools rely on school district such as the filters. Digital citizenship performance in schools is in low level. In addition, most digital citizenship performance focused on legal use of technology. For instance, provide technology usage guidelines for students and teachers to make them aware of dos and don't in digital learning environment.

Indicators of digital age learning culture are new findings as well. Creating and sustaining digital learning environment is the most important thing for schools. Digital learning environment indicators include digital resources and technology modeling. Providing necessary hardware is the basis of digital learning. If students do not have access to devices, digital learning does not exist. For instance, if schools do not have Wifi, students and teachers can do nothing with the computers. The money spent on the devices is kind of waste. In addition, teachers and students need to learn how to use technology besides just copy the information from books to computer. Showing the same information from the books is not using technology. Principals can demonstrate the value of technology through the daily interaction with the teachers. For example, showing how teachers are evaluated through iPad can help teachers see actual examples. Teachers would consider how she can use the same technology to evaluate her students. 
Findings related to visionary leadership and professional development similar findings to prior studies (Chang, 2012; Duncan, 2011).To successfully inspire and lead schools' digital transformation and meet the requirement of visionary leadership, awareness of digital management and support from all stakeholders are two important factors that K-12 principals need to be equipped with. Principals first need to realize the importance of technology so that they can model the use of technology in school management and help all stakeholders see the benefits of digital environment. Parents and teachers are easier to accept and choose digital learning and teaching environment after they see and feel the value of technology. For instance, providing opportunities of accessing digital learning environment for parents is a good strategy to promote digital leadership. Requiring teachers attend necessary training also is important for teachers to understand how students can benefit from digital learning environment. Digital learning opportunities and digital learning community are two indicators of excellence in professional practice. Providing professional development opportunities does not mean asking teachers to participate in the trainings. The point is to ensure teachers can get practical information from the professional development opportunities. If teachers cannot take things from the professional development opportunities, then it is waste of time for teachers. One strategy is to work with the trainers to ensure the trainers are offering the things teachers want and need. Digital learning community is not only important for students but also is a great way for teachers to communicate and collaborate. Learning community provides teachers an opportunity of sharing information and learning from each other. For instance, teachers can share their experiences of using specific tools or apps. Teachers who are not good at technology may want to try after they hear from their colleagues. Learning community does not only mean face-to-face talking. Effectively use social media such as Twitter can get more stakeholders involved. For example, sharing digital resources at Twitter so that everyone in the community can see it. The more opportunities teachers getting involved in digital learning environment, teachers are more likely to improve technological skills.

Part findings of systemic improvement were mentioned in prior studies (Chang, 2012; Duncan, 2011; Garcia, 2014). Maximized learning achievement, competent personnel, and strategic partnership are indicators of systematic improvement. Technology should be embedded in organizational development so that digital leadership and digital learning can be accepted and supported by all the stakeholders. For instance, giving reward to the highly competent persons and making school administration apparent are suggested strategies by all the principals.

\section{Limitation}

This study is limited to the location of the participants. All participants came from the same district. Within the same school district, principals may share the same technology resources such as evaluation software, iPad apps, and management programs. Generalization of this study may be hurt by this limited location of participants. In addition, all participants are female principals. Including male principals can strengthen the generalization of the findings as well. Principal's age may also matter because younger principals may be more active in technology integration than older principals. Including more younger principals can improve this study's generalization. Future study is suggested to include more participants from various school districts to examine indicators of digital leadership at 
K-12 schools. In addition, it will be beneficial to include other school levels such as upper elementary schools and middle schools to explore how digital leadership looks like in those schools. In addition, quantitative study is recommend to examine the indicators of digital leadership at K-12 schools.

\section{Conclusion}

This qualitative case study investigated the indicators of digital leadership based on the ISTE-A standards. Three K-12 principals were interviewed with in-depth questions and results showed that principals in digital age should be able to inspire and lead school transformation through technology, create and sustain digital learning culture, support technology-based professional development, provide digital leadership and management, and facilitate and manage social, ethical, and legal issues. Indicators of digital leadership constitute awareness of digital leadership, support from all stakeholders, digital resources, technology modeling, practical professional development, digital learning community, maximized learning achievement, competent personnel, strategic management, robust infrastructure, technology agreement form, and filters.

With continuous influence on education, technology is part of today's learning. Principals should not ignore technology integration into K-12 learning and teaching. The role of the principal has changed from solely a school administrator to the multifaceted role of curricular and technological leader. Principals should guide teachers to improve their technological literacy, teaching effectiveness, and students' academic achievements through technology. Effective communication and collaboration also improve the effectiveness of leading educational reform and enhance learning and teaching. This study acts as a reference for K-12 principals regarding digital leadership application in K-12 schools. One important thing for principals to remember is that while supporting technology integration and carrying out digital leadership, they should not only focus on hardware. It is important and necessary to provide teachers with hands-on resources that they can use in their classrooms immediately. 


\section{References}

Chang, I. H. (2012). The effect of principals' technological leadership on teachers' technological literacy and teaching effectiveness in Taiwanese elementary schools. Educational Technology \& Society, 15(2), 328-340.

Creswell, J. R. (2013). Qualitative inquiry research design: Choosing among five approaches (3rd ed.). Thousand Oaks: Sage Publications.

Garcia, A. \& Abrego, C. (2014). Vital skills of the elementary principal as a technology leaders. Journal of Organizational Learning and Leadership, 12(1), 12-25.

Hadjithoma-Garstka, C (2011). The role of the principal's leadership style in the implementation of ICT policy. British Journal of Educational Technology, 42(2), 311-326.

ISTE. (2009). National Educational Technology Standards for Administrators 2009. Retrieved from http://www. iste.org/Libraries/PDFs/NETS for Administrators 2009 EN.sflb.ashx.

Karnjanapun, S. (2013). Teachers' technology leadership assessment: A comparative case study of Thailand and the U.S.A. In. Jan Herrington et al. (Eds.), Proceedings of World Conference on Educational Multimedia, Hypermedia and Telecommunications 2013, 2099-2107. Chesapeake, VA: AACE.

Jan, A. Q. (2012). Exploratory study of a principal's teachnology (ICT) leadership practices in the rural context of Pakistan (Unpublished master's dissertation). Aga Khan University, Karachi, Pakistan.

Metcalf, W. (2012). K-12 principals' perceptions of their technology leadership preparedness. Electronic Theses \& Dissertations. Paper 400.

PTLA-Principals Technology Leadership
Assessment (2006). UCEA Center for the Advanced Study of Technology Leadership in Education, University of Minnesota. Retrieved from http://www. schooltechleadership.org/.

Pritchard, K. (2014). Recommendations for K-12 administrators for technology integration. In M. Searson \& M. Ochoa (Eds.), Proceedings of Society for Information Technology \& Teacher Education International Conference 2014, 957-961. Chesapeake, VA: AACE.

Raman, A., Don, Y., and Kasim, A. L. (2014). The relationship between principals' technology leadership and teachers' technology use in Malaysian secondary school. Asian Social Science, 10(18), 3036.

Richardson, J. W., Bathon, J., Flora, K. L., \& Lewis, W. D. (2012). NETS-A scholarship: A review of published literature. Journal of Research on Technology in Education, 45(2), 131-151.

Seidman, I. (2012). Interviewing as qualitative research: A guide for researchers in education and the social sciences (4th ed.). New York: Teachers College Press.

Weng, C. \& Tang, Y. (2014). The relationship between technology leadership strategies and effectiveness of school administration: An empirical study. Computers \& Education, 76(1), 91-107.

Yin, R. K. (2013). Case study research: Design and methods (5th ed.). Thousand Oaks: Sage Publications.

\section{Contact the Author}

\section{Dr. Lin Zhong}

Assistant Professor of Department of Workforce Education and Development College of Education and Human Services Southern Illinois University

Carbondale, Illinois, USA

Email: lin.zhong@siu.edu 


\section{Appendix}

Interview Questions

\section{Visionary Leadership}

1. What does technology mean to you?

2. How do you inspire and facilitate among all stakeholders a shared vision of purposeful change that maximizes use of digital-aged resources to meet and exceed learning goals, support effective instructional practice and maximize performance of district and school leaders?

3. How do you engage in an ongoing strategic plans aligned with a shared vision?

4. What activities do you take to advocate on local, state, and national levels for policies, programs, and funding to support implementation of a technology-infused vision and strategic plan.

\section{Digital Age Learning Culture}

1. What strategies do you take to ensure instructional innovation focused on continuous improvement of digital age learning?

2. What methods do you use to model and promote the frequent and effective use of technology for learning?

3. What do you do to provide learner-centered environments equipped with technology and learning resources to meet the individual, diverse need of all learners?

4. How do you ensure effective practice in the study of technology an its infusion across the curriculum?

\section{Excellence in Professional Practice}

1. Do you allocate time, resources, and access to ensure ongoing professional growth in technology fluency and integration?

2. Do you facilitate and participate in learning communities that stimulate, nurture, and support administrators, faculty, and staff in the study and use of technology?

3. How do you promote and model effective communication and collaboration among skate holders using digital age tools?

4. What do you do to stay abreast of educational research and emerging trend regrading effective use of technology and encourage evaluation of new technologies for their potential to improve student learning? 


\section{Systemic Improvement}

1. How do you lead purposeful change to maximize the achievement of learning goals through the appropriate use of technology and media-rich resources?

2. How do you collaborate to establish metrics, collect and analyze data, interpret results, and share findings to improve staff performance and student learning?

3. What strategies do you use to recruit and retain highly competent personnel who use technology creatively and proficiently to advance academic and operational goals?

4. How do you establish and leverage strategic partnerships to support systemic improvement?

5. How do you establish and maintain a robust infrastructure for technology including integrated, interoperable technology systems to support management, operations, teaching, and learning?

\section{VI.Digital Citizenship}

1. How do you ensure equitable access to appropriate digital tools and resources to meet the needs to all learners?

2. How do you promote, model, and establish policies for safe, legal, and ethical use of digital information and technology?

3. What do you do to promote and model responsible social interactions related to the use of technology and information?

4. How do you model and facilitate the development of a shared cultural understanding and involvement in global issues through the use of contemporary communication and collaboration tools? 